\title{
Phase Structure and Mechanical Properties of Blends of Poly(ether imide) and Bisphenol A Polycarbonate
}

\author{
Jorge RAMIRo, José Ignacio EgUIAZÁBAL, ${ }^{\dagger}$ and Jon NAZÁBAL \\ Dpto. de Ciencia y Tecnología de Polímeros and Instituto de Materiales Poliméricos "POLYMAT", \\ Facultad de Ciencias Químicas, UPV-EHU, P.O. Box 1072, 20080 San Sebastián, Spain
}

(Received December 26, 2003; Accepted June 7, 2004; Published September 15, 2004)

\begin{abstract}
Poly(ether imide) (PEI)/bisphenol A polycarbonate (PC) blends were obtained throughout the composition range both by direct injection moulding (DI blends) and by extrusion followed by injection moulding (PM blends). Although some reaction was observed by FT IR, the blends were fully phase separated at the detection level of DMTA. An anomalous decrease in the high temperature $T_{\mathrm{g}}$ of the $90 / 10$ and 80/20 blends, was only seen in PM blends. This was attributed to an anomalous thermodynamic behaviour, after rejecting degradation, reactions or particle size as possible explanations. With the exception of the PC-rich DI blends, the morphology was fine and homogeneous. Both the modulus of elasticity and the yield stress were very close to those expected from the rule of mixtures, whatever the morphology. Unexpectedly, ductility followed the same trend, even in the less homogeneous PC-rich DI blends. This points to the very slight reactions observed, and to parameters related to chemical features of the components (such as the highly aromatic character of the components of the blend) as the main reasons for the observed ductility behaviour. [DOI 10.1295/polymj.36.705]

KEY WORDS Poly(ether imide) / Polycarbonate / Blends / Mechanical Properties / Phase Structure /
\end{abstract}

Blending thermoplastic polymers ${ }^{1,2}$ to obtain multicomponent materials is one of the most useful ways to develop new polymeric materials. This is because the costs associated with the development of a new polymer do not usually compensate the likely profit. Moreover, the preparation and development of blends based on commercial polymers requires less time for the optimisation of the final product. Usually, the components of a blend are selected looking at complementary characteristics in processability, final properties or price. Thus, polymer blending can allow the combination, for example, of an expensive high performance polymer with a cheaper one, to obtain the expected performance at an advantageous cost.

Poly(ether imide) (PEI) is a high performance amorphous thermoplastic with good thermal stability $\left(T_{\mathrm{g}}=220^{\circ} \mathrm{C}\right)$ and remarkable modulus of elasticity and tensile strength. ${ }^{3}$ It is used, among other applications, for advanced parts in electrical and electronics industry, in aircraft applications and in the automotive industry. Blends of PEI with poly(ether ether ketone) (PEEK), ${ }^{4-6}$ aliphatic-aromatic polyesters, ${ }^{7-20}$ polyarylate (PAr), ${ }^{21,22}$ polyamide $6,6,{ }^{23,24}$ poly(phenylene sulphide) (PPS) and polysulfone of bisphenol A (PSU) ${ }^{25}$ among others, have been studied and several patents ${ }^{26}$ with polymers such as polycarbonate, polyamides, polypropylene, polysulfones and liquid crystal polymers, have been granted.
Bisphenol A polycarbonate (PC) is an engineering thermoplastic with applications in a wide variety of fields, such as electronics, illuminating engineering, household, automotive industry, sports, security elements, etc. Its blends with many other polymers have been studied ${ }^{27,28}$ or registered, ${ }^{26}$ and some of them such as those with poly(ethylene terephthalate) (PET), poly(butylene terephthalate) (PBT), thermoplastic polyurethanes and ABS, are commercial materials. $^{26}$

A PEI/PC blend has been commercialised by General Electric under the trade name Ultem LTX, and some patents covering PEI/PC blends have been registered. ${ }^{29-32}$ The miscibility ${ }^{33}$ of PEI/PC blends, their phase structure and their thermodynamic behaviour ${ }^{34}$ were analysed recently; as well as the yield stress and impact strength of blends with PEI contents below $20 \% .{ }^{35}$ The patents analysed mechanical and thermal properties of some compositions, ${ }^{29}$ as well as the impact modification ${ }^{31}$ and melt stabilization ${ }^{30}$ of the blends. Flame retardant PEI/PC blends were also described. ${ }^{32}$ However, no systematic study on the structure and properties of PEI/PC blends has been published, to our knowledge, in the open literature.

In this work, the thermal properties, morphology and mechanical behaviour of PEI/PC blends have been studied across the whole composition range. The blends have been prepared both by direct injec-

${ }^{\dagger}$ To whom correspondence should be addressed (E-mail: popegori@sq.ehu.es). 
tion moulding and by extrusion followed by injection moulding. Their phase structure was analysed by differential scanning calorimetry (DSC) and dynamicmechanical analysis (DMTA), and their morphology by scanning electron microscopy (SEM). The mechanical properties were determined by means of tensile and impact tests.

\section{EXPERIMENTAL}

The PEI used was Ultem 1000 (General Electric Co.). Its melt flow index is $8.5 \mathrm{~g} / 10 \mathrm{~min}$, as determined at $337^{\circ} \mathrm{C}$ and with a $6.7 \mathrm{~kg}$ load (ASTM D1238). The PC was Makrolon 2805 (Bayer AG). Its melt flow index is $8 \mathrm{~g} / 10 \mathrm{~min}$, at $300^{\circ} \mathrm{C}$ and with a $1.2 \mathrm{~kg}$ load (ASTM D1238). PEI and PC were dried before processing in an air oven; PEI at $150^{\circ} \mathrm{C}$ for $4 \mathrm{~h}$; and $\mathrm{PC}$ at $120^{\circ} \mathrm{C}$ for $10 \mathrm{~h}$. Two different processing methods were used. Premixed blends (PM) were obtained by extrusion mixing PEI and PC, followed by injection moulding. Directly injection moulded (DI) blends were obtained from dry mixtures of pellets without previous melt mixing.

Premixing of the PM blends was carried out in a corotating twin screw extruder-mixer (Collin ZK-25) at $300-310^{\circ} \mathrm{C}$. The screw speed was $30 \mathrm{rpm}$, and the obtained rod extrudates were cooled in a water bath and then pelletized. Both the PM and DI blends were injection moulded in a Battenfeld BA 230E reciprocating screw injection moulding machine using a barrel temperature of $330^{\circ} \mathrm{C}$, a mould temperature of $35^{\circ} \mathrm{C}$, an injection speed of $8.5 \mathrm{~cm}^{3} / \mathrm{s}$ and injection pressure of $2250 \mathrm{bar}$. The mould provided tensile (ASTM D638, type IV) and impact (ASTM D256) specimens.

Calorimetric analyses (DSC) of the neat components and of the blends were performed using a PerkinElmer DSC-7 differential scanning calorimeter. The samples were first heated from $30^{\circ} \mathrm{C}$ up to $270^{\circ} \mathrm{C}$ at $20^{\circ} \mathrm{C} / \mathrm{min}$, then cooled at the maximum available rate (approximately $100^{\circ} \mathrm{C} / \mathrm{min}$ ) and reheated. The glass transition temperatures $\left(T_{\mathrm{g}}\right)$ were determined in the second heating scan. DMTA analysis was performed using a Polymer Laboratories DMTA that provided the plots of the loss tangent $(\tan \delta)$ and the storage modulus $\left(E^{\prime}\right)$ against temperature. The scans were carried out in single cantilever mode at a constant heating rate of $4^{\circ} \mathrm{C} / \mathrm{min}$ and at a frequency of $1 \mathrm{~Hz}$, from $80^{\circ} \mathrm{C}$ to $250^{\circ} \mathrm{C}$.

Specific volume values were measured by the displacement method in a Mirage SD-120L electronic densitometer with a resolution of $0.0003 \mathrm{~cm}^{3} / \mathrm{g}$, using butyl alcohol as the immersion liquid. The melt flow indexes (MFI) of the blends were measured (ASTM D1238) using a Ceast extrusion plastometer at $300^{\circ} \mathrm{C}$ and with a $3.8 \mathrm{~kg}$ load. Vicat softening points were measured with an ATS-Faar MP3 HDT-Vicat tester, at $50^{\circ} \mathrm{C} / \mathrm{h}$ and with a $1 \mathrm{~kg}$ load (ASTM D1525) using impact specimens.

The surfaces of cryogenically fractured specimens were observed by SEM after gold coating. A Hitachi S-2700 electron microscope was used at an accelerating voltage of $15 \mathrm{kV}$.

Tensile tests were carried out in an Instron 4301 at $23^{\circ} \mathrm{C}$ and at a crosshead speed of $10 \mathrm{~mm} / \mathrm{min}$. The mechanical properties (Young's modulus, yield and break stresses and break strain) were determined from the load-elongation curves. Izod impact tests were carried out using a Ceast pendulum on notched specimens (notch depth $2.54 \mathrm{~mm}$, notch radius $0.25 \mathrm{~mm}$ ). The notches were machined after moulding. At least eight specimens were tested for each determination in both the tensile and impact tests.

\section{RESULTS AND DISCUSSION}

\section{Phase Behaviour}

Figure 1 shows the $T_{\mathrm{g}}$ values obtained by DSC and DMTA for DI blends. As usual, the $T_{\mathrm{g}}$ 's determined by DMTA were generally slightly higher than those measured by DSC. They are also usually more accurate and sensitive to slight transitions. As can be seen, two practically constant $T_{\mathrm{g}}$ 's were observed by both techniques, although the $T_{\mathrm{g}}$ of the minority component was unobservable in blends very rich in the other component. The $T_{\mathrm{g}}$ 's were almost identical to those of the neat components, indicating the presence in the blends of two practically pure phases and, consequently, the total immiscibility of the blends.

Figure 2 shows the DSC and DMTA results for PM blends. As can be seen, the low temperature $T_{\mathrm{g}}$ of the blends was very close to that of PC. In the $80 / 20$ blend, the $T_{\mathrm{g}}$ by DSC decreased. This decrease was attributed to the experimental error associated with the low PC content and the weak intensity of its transition by DSC, because no clearly significant change $\left(2^{\circ} \mathrm{C}\right)$ was observed by DMTA. As can also be seen, the high temperature $T_{\mathrm{g}}$ of the blends with PEI contents below $80 \%$, was very similar to that of the neat PEI. However, the high temperature $T_{\mathrm{g}}$ of the $80 / 20$ and $90 / 10$ blends decreased $6{ }^{\circ} \mathrm{C}$ and $9{ }^{\circ} \mathrm{C}$ respectively. These decreases were significant and have been observed previously. ${ }^{33,34}$

These decreases in $T_{\mathrm{g}}$ of the PM 90/10 and 80/20 blends cannot be due to partial miscibility, since a polymer-polymer interaction parameter $\left(\chi_{12}\right)$ between 0.213 and 0.246 was reported for PEI/PC blends. ${ }^{36}$ Moreover, in a partially miscible blend, the shift of the high temperature $T_{\mathrm{g}}$ should be more pronounced at increasing contents of the low $T_{\mathrm{g}}$ polymer, whereas 


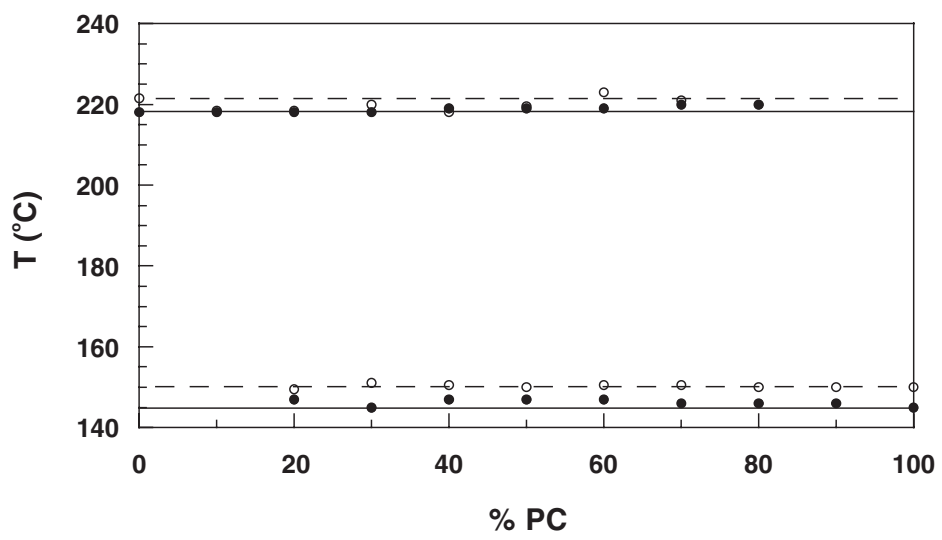

Figure 1. Glass transition temperatures of DI blends measured by DSC $(\bullet)$ and DMTA $(\bigcirc)$, as a function of the composition.

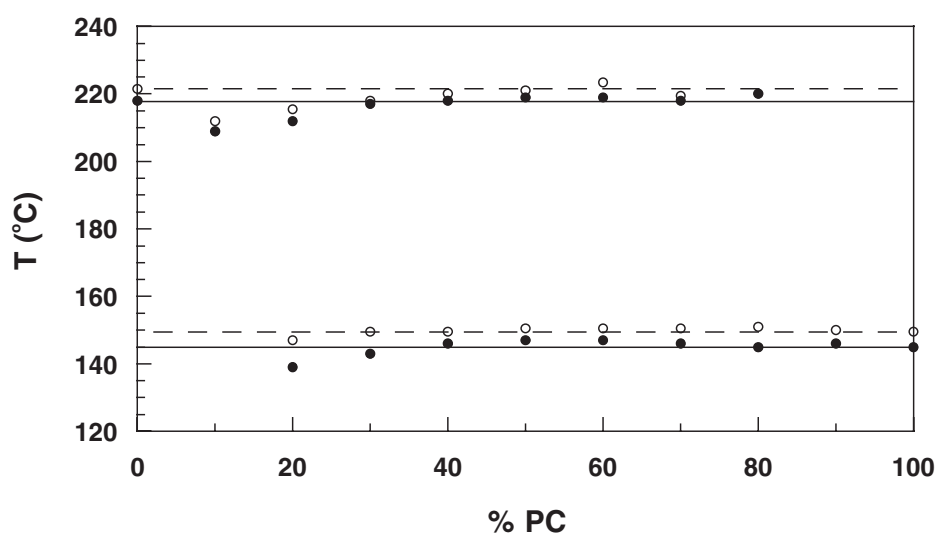

Figure 2. Glass transition temperatures of PM blends measured by DSC $(\bullet)$ and DMTA $(\bigcirc)$, as a function of the composition.

the opposite behaviour was observed. These anomalous $T_{\mathrm{g}}$ decreases in these PEI/PC blends, have been attributed to the small particle size of the blends, ${ }^{33}$ to transpolymerization reactions, ${ }^{30}$ and to an anomalous thermodynamic behaviour of the blends. ${ }^{34} \mathrm{Be}$ sides these possibilities, they could also be due to degradation, because the decreases were clearly seen in previously extruded PM blends, but they were not detected in the directly mixed DI blends, for which the processing time was shorter. Degradation can give rise to low molecular weight species able to plasticize the continuous phase. Thus, the experimental results of this study using different processing procedures contribute additional experimental evidence to the interpretation of this anomalous $T_{\mathrm{g}}$ behaviour.

To test the possibility of degradation, the MFI's of the neat components, and of the $80 / 20$ and $90 / 10$ blends obtained by both processing methods, were measured. The possibility to use a more sensitive technique, such as FT IR, was discarded because, as previously seen, ${ }^{37,38}$ the FTIR spectra of PEI and PC do not change as a consequence of degradation during processing. The MFI values of the blends obtained by both processing methods were similar. Deg- radation without significant change in viscosity can also take place. However, decreases in the $T_{\mathrm{g}}$ of the PEI phase of $5-6^{\circ} \mathrm{C}$ in the $80 / 20$ and $90 / 10$ compositions respectively, were seen in blends prepared by solution casting. ${ }^{33}$ Hence, degradation is ruled out as the reason for the observed anomalous $T_{\mathrm{g}}$ behaviour.

The size of the dispersed phase in a blend can affect the $T_{\mathrm{g}}$ value measured, and also the range and intensity of the transition. ${ }^{39}$ In the limit, when the dispersed phase size is smaller than the sensitivity of the technique, although the blend is not mixed at a segmental level, an apparent miscible behaviour can be observed. Thus, a single loss maximum was observed $^{39,40}$ in a biphasic blend, when the specific relative surface (the area of the total surface per volume unit of the dispersed phase) of the blend was higher than $25 \mu \mathrm{m}^{-1}$; thus, in the case of spherical particles, at a diameter of $0.24 \mu \mathrm{m}$ or less. As stated later, the diameter of the dispersed PC particles was close to this value; so the observed decrease in $T_{\mathrm{g}}$ could in part be due to this particle size effect. However, in this study, a small particle size appeared in PM blends, but also in the DI blends where the anomalous $T_{\mathrm{g}}$ decreases did not take place. So, a small particle size 
that would make the blends appear as miscible or partially miscible is not the reason for the observed behaviour.

In a patent on PEI/PC blends, ${ }^{30}$ a single $T_{\mathrm{g}}$ was observed after mixing for $9 \mathrm{~min}$ at temperatures above $300{ }^{\circ} \mathrm{C}$ in a discontinuous mixer. This result was attributed to the development of transpolymerization reactions between both blend components. The presence of reactions could explain the observed difference in $T_{\mathrm{g}}$ behaviour of DI and PM blends, as reactions are more probable in the longer PM procedure. Thus, in order to check the existence of reactions in the 80/ 20 and 90/10 blends, the FT IR spectra of the 90/10 and 70/30 PM blends, and the corresponding theoretical spectra obtained by weighted addition of those of the neat components, were obtained and are shown in Figure 3a. As can be seen, the theoretical and the experimental spectra of the $90 / 10$ blend were similar, but some changes were seen in the $1150-1200 \mathrm{~cm}^{-1}$ region. This indicates a change in the chemical structure due to reactions, that were perhaps affected by the additives which were probably present in commercial

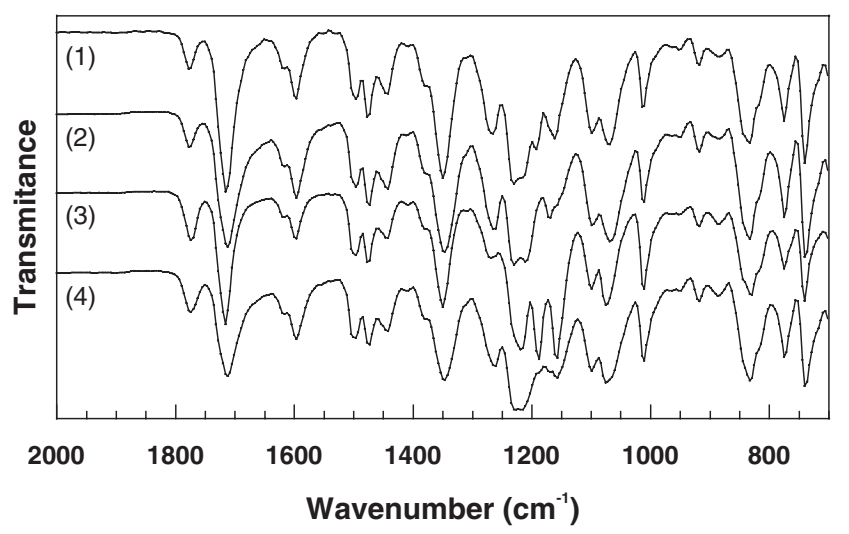

(a)

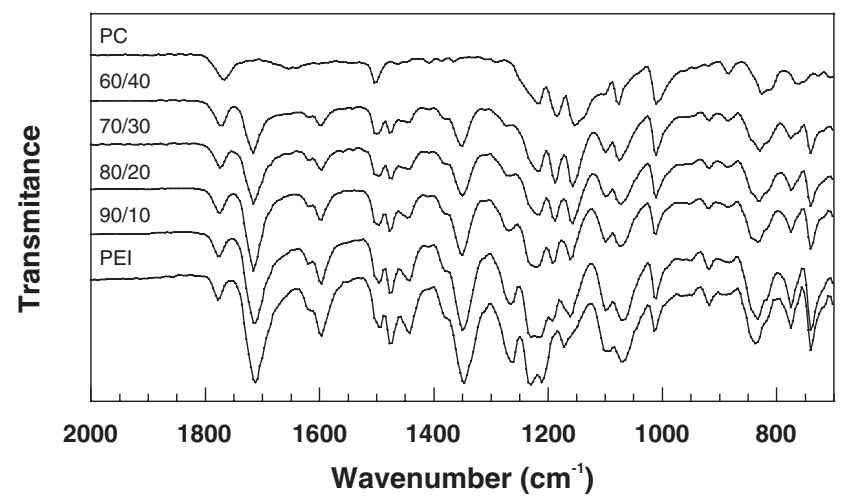

(b)

Figure 3. (a) FT IR spectra of (1) PEI/PC (90/10) PM blend, (2) the weighted addition of $90 \%$ PEI and $10 \%$ PC, (3) PEI/PC (70/30) PM blend and (4) the weighted addition of 70\% PEI and $30 \%$ PC. (b) FT IR spectra of PM blends as a function of composition.
PEI and PC samples. The evolution of the FT IR profiles with the blend composition (Figure $3 b$ ) did not contribute to a better understanding of the nature of the reacted products. In any case, reactions were not the reason for the observed $T_{\mathrm{g}}$ behaviour as the observed changes also appeared in the 70/30 blend of Figure $3 \mathrm{a}$, where no $T_{\mathrm{g}}$ decrease was seen.

Finally, with respect to some anomalous thermodynamic behaviour in the blends, molecular dynamics simulations showed $^{34}$ that the Flory-Huggins interaction parameter reached a minimum value at $80 \%$ PEI, and that its concentration dependence was mainly due to electrostatic interactions and Van der Waals forces. The results of this study agree with this explanation, as the $T_{\mathrm{g}}$ decreases appeared in PM blends where the blends were intimately mixed. However, these $T_{\mathrm{g}}$ decreases did not appear in DI blends where the thermodynamic equilibrium had to be farther, due to the short mixing time and the poorer mixing.

\section{Morphology}

The morphology of the cryogenically fractured tensile specimens was observed by SEM. Figure 4 shows the fracture surfaces of the DI blends. As can be seen, the 90/10 blend (Figure 4a) showed dispersed spherical particles, mostly close to $0.3 \mu \mathrm{m}$ diameter, which were difficult to observe. Large holes (close to $1 \mu \mathrm{m}$ ) were also seen, indicating that blending was not homogeneous. As can be seen in Figure 4b, the 70/ 30 composition showed, besides some dispersed particles, a close to co-continuous structure. This type of morphology is characteristic of the phase inversion that, therefore, takes place at PEI-rich compositions. This is in agreement with the higher melt viscosity of PEI, that tends to be encapsulated by the less viscous PC. In the 50/50 blend (Figure 4c) the morphology was also close to co-continuous and the morphology changed. Therefore, phase inversion must have taken place. In the 30/70 and 10/90 blends of Figures $4 \mathrm{~d}$ and $4 \mathrm{e}$, respectively, the dispersed particle size was large, indicating poor mixing. Thus, particle size was mostly $2 \mu \mathrm{m}$ in the $30 / 70$ blend; in the two blends of Figures $4 \mathrm{~d}$ and $4 \mathrm{e}$ PEI particles with size below $0.5 \mu \mathrm{m}$, as well as agglomerates of several microns were seen. In addition, some slightly elongated particles, probably due to the shear flow during mould filling, were seen throughout the cross section.

As can also be seen in Figure 4, the average particle size of the PC-rich blends was clearly larger than that of PEI-rich blends. A number of parameters influence the particle size generated during the processing of polymer blends. ${ }^{41,42}$ Among them, the viscosity ratio is largely definitive. This is because when the viscosity of the matrix is higher than that of the dispersed component, the matrix will be able to deform easily 


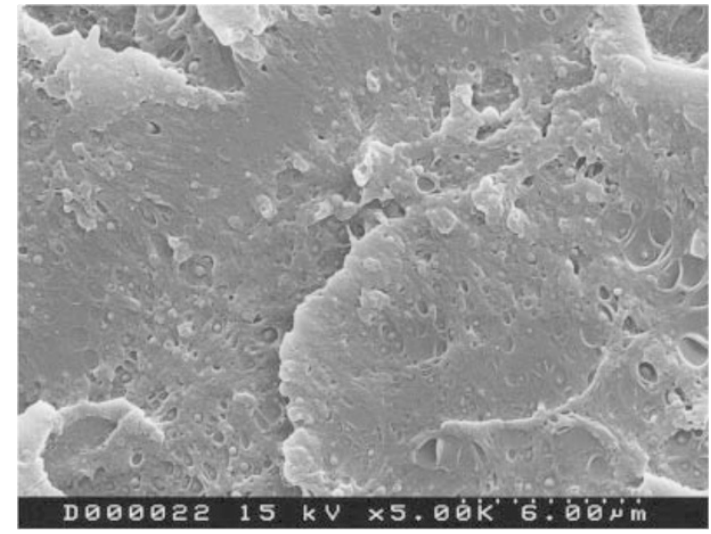

(a)

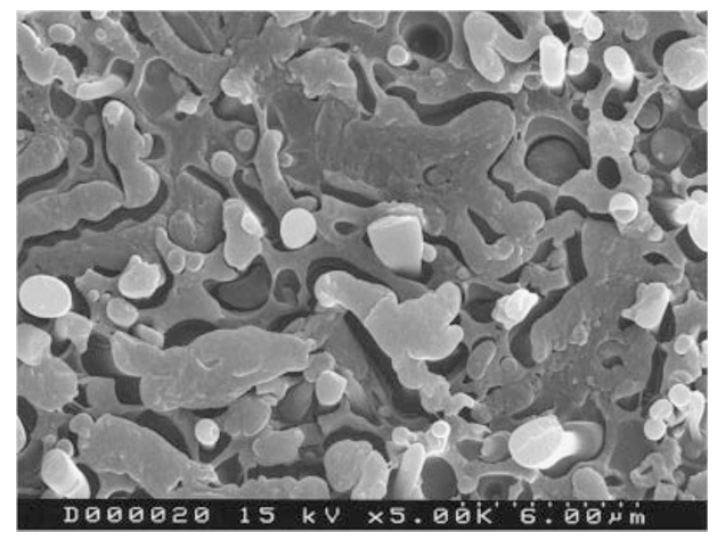

(b)

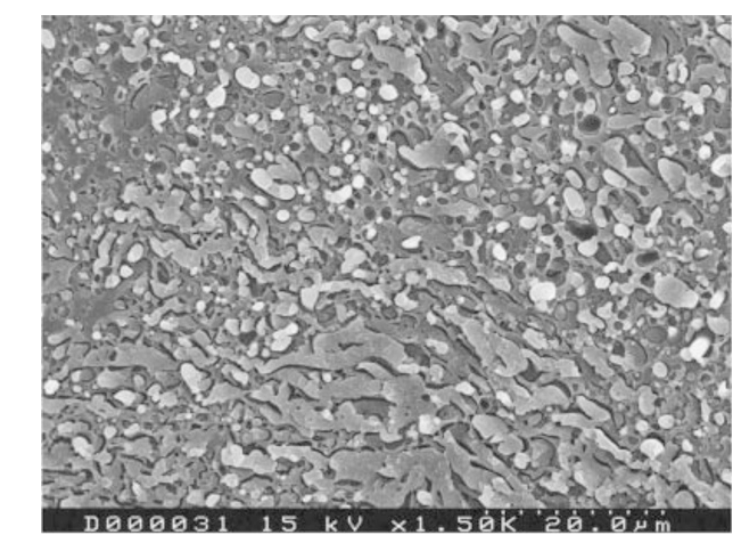

(c)

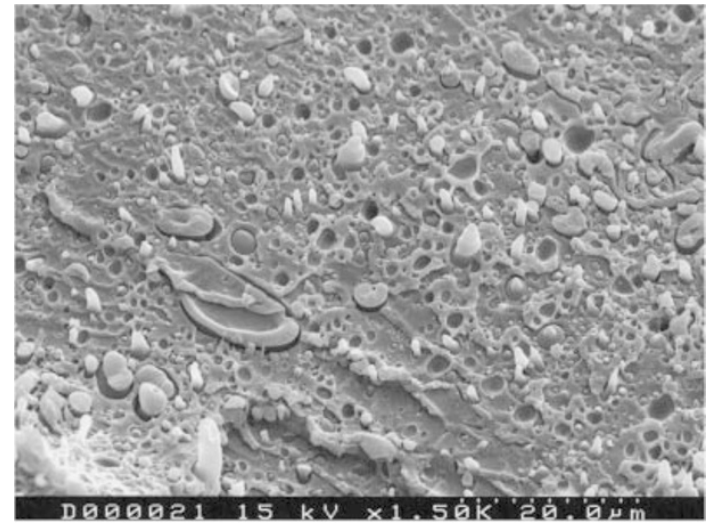

(d)

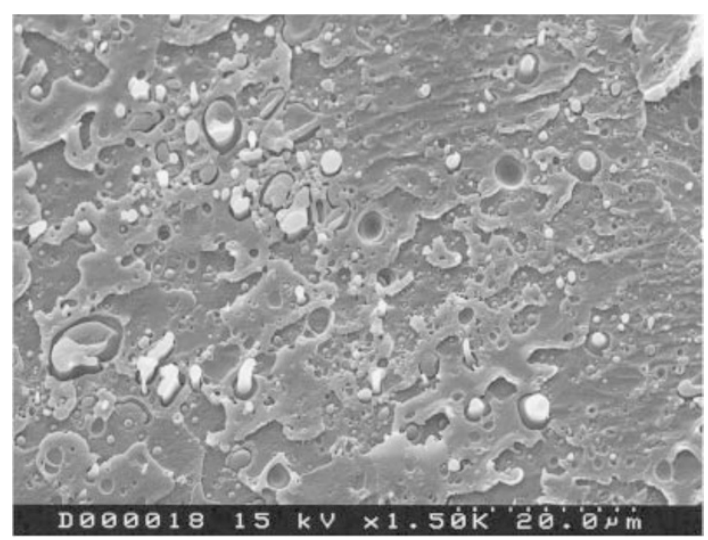

(e)

Figure 4. SEM microphotographs of cryogenically fractured specimens of (a) 90/10, (b) 70/30, (c) 50/50, (d) 30/70, and (e) $10 / 90$ DI blends.

and break the dispersed component, leading to a fine dispersed phase. ${ }^{42}$ This led the particle size to be smaller when the highly viscous PEI was the continuous phase. With respect to adhesion, although the fracture surfaces were rather clean, the fact that some particles appeared broken indicated that some adhesion existed at the interface.

Figure 5 shows the morphology of the PM blends. In the blend with 90\% PEI (Figure 5a), the dispersed phase was finely distributed in the form of small spheres with a particle size similar to that predominantly seen in Figure 4a. However, the morphology was homogeneous as no large particle was observed and the particle size dispersion was low. The morphology of the 70/30 blend (Figure 5b) was rather co-continuous, as in the case of Figure $4 \mathrm{~b}$. The morphology of the 50/50 blend of Figure 5c was farther from cocontinuity than that of Figure 4c. This indicated a nar- 


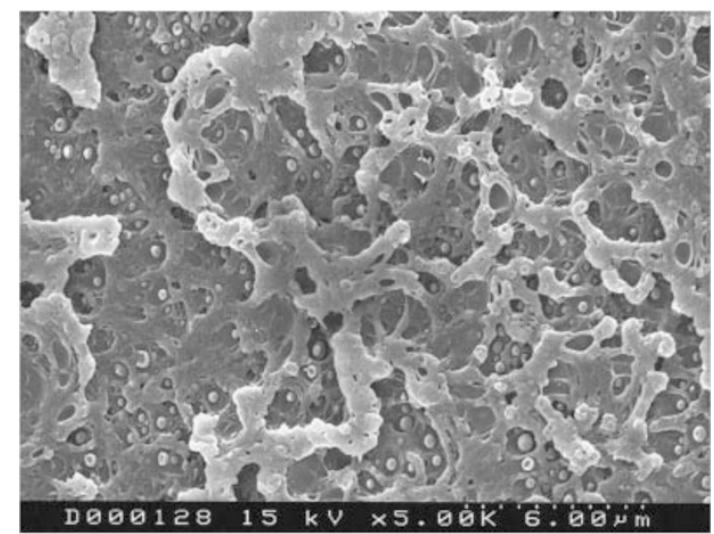

(a)

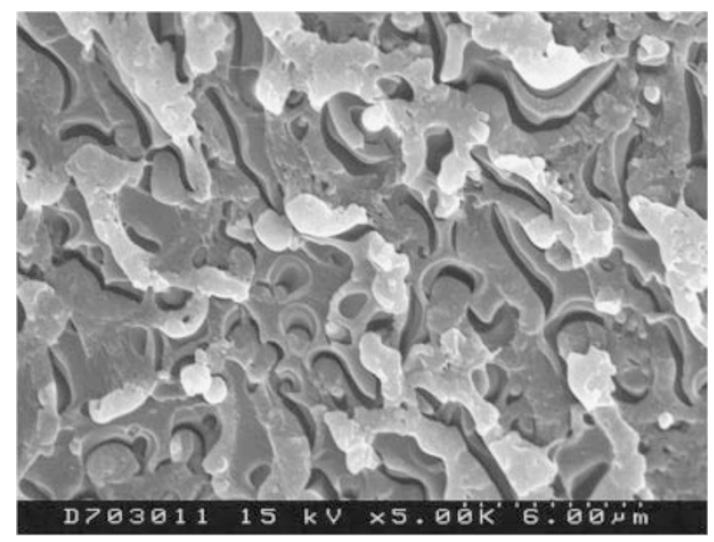

(b)

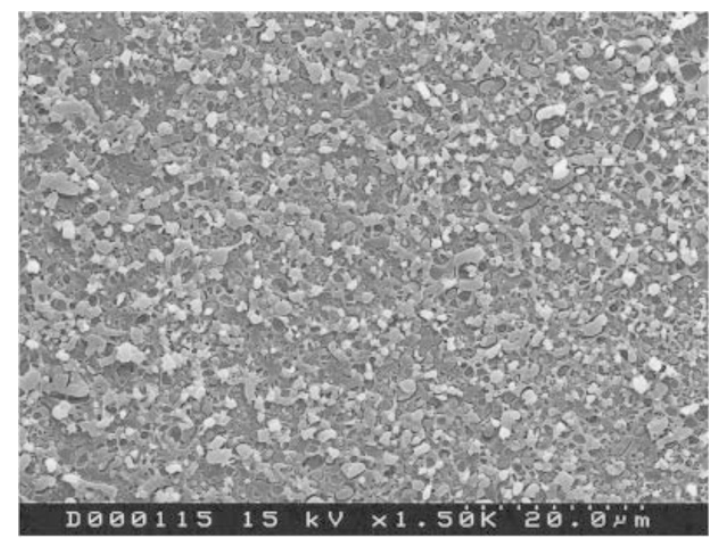

(c)

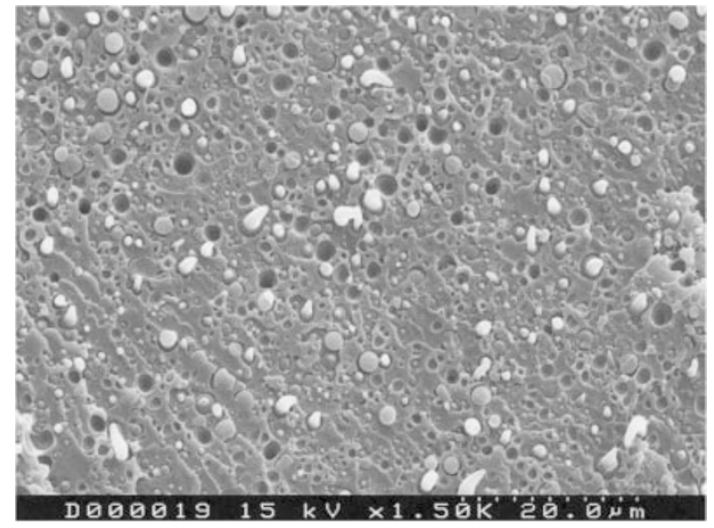

(d)

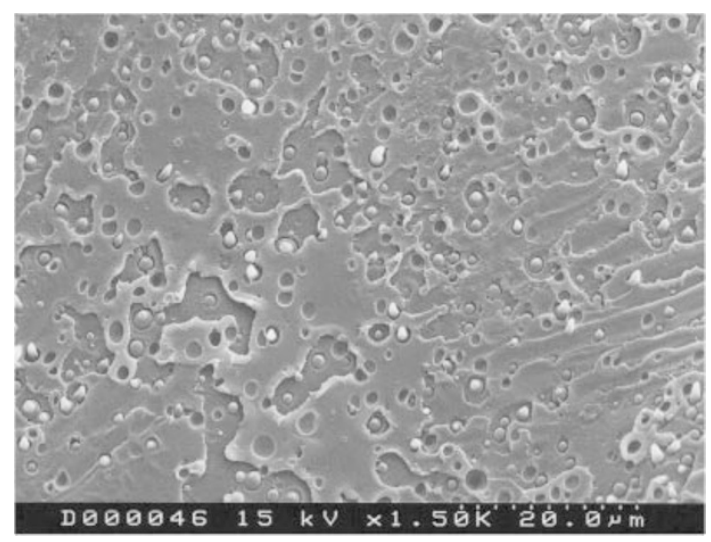

(e)

Figure 5. SEM microphotographs of cryogenically fractured specimens of (a) 90/10, (b) 70/30, (c) 50/50, (d) 30/70, and (e) 10/90 PM blends.

rower phase inversion range in the PM blends, that also indicated a better mixing. ${ }^{41}$ Finally, Figures $5 \mathrm{~d}$ and $5 \mathrm{e}$ show the fracture surfaces of the PM blends with 30 and $10 \%$ PEI, respectively. As can be seen, the mixing level was also clearly better than that of DI blends, as no agglomerate appeared. Moreover, the average particle size was smaller, and the particle size distribution narrower than in DI blends. As in DI blends, some elongated particles appeared. With the exception of the 70/30 composition, no fractured particle was seen in these blends. This was probably due to their smaller particle size and was not indicative of poor adhesion, as after fracture some particles remained linked to the continuous phase.

The Vicat softening temperature-composition relationship has been used to study the phase behaviour of amorphous blends ${ }^{43}$ and the composition of the phase inversion. The Vicat temperatures of both DI and PM 


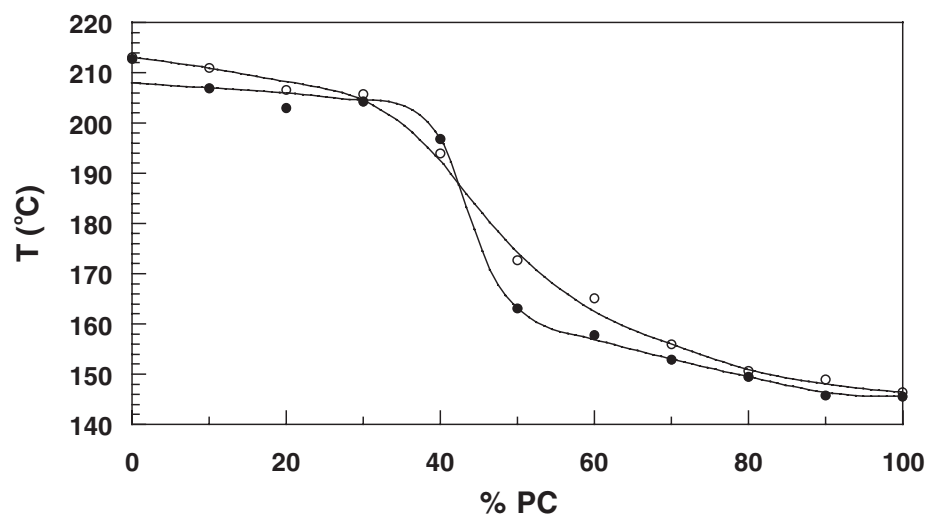

Figure 6. The Vicat softening temperature of DI $(\bigcirc)$ and PM (๑) blends as a function of composition.

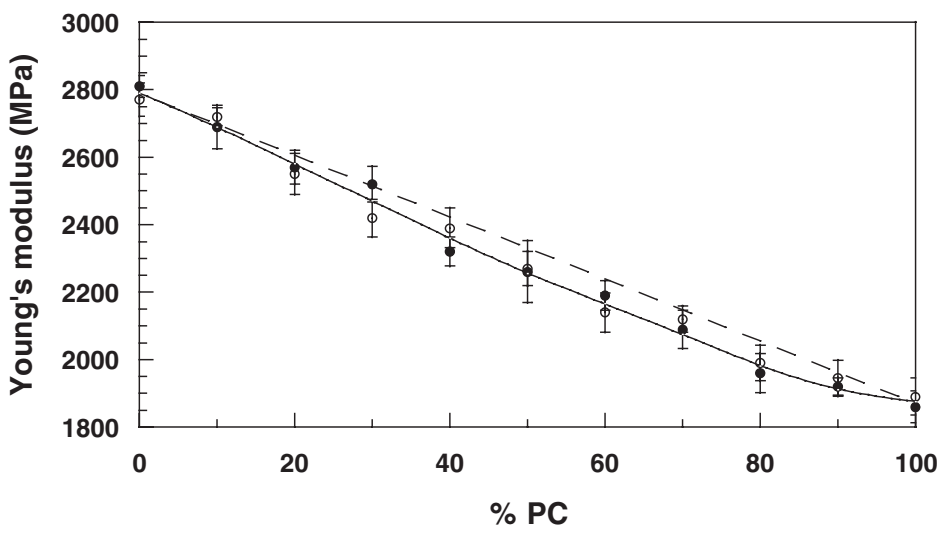

Figure 7. Young's modulus of the blends as a function of the composition. Symbols as in Figure 6.

blends are shown in Figure 6. As can be seen, as expected for a biphasic blend, the plots were sigmoidal. The phase inversion composition should correspond ${ }^{43}$ to the inflexion point. It appeared between 60 and $50 \%$ PEI, in agreement with the observed morphologies. Moreover, the inflexion range was narrower in $\mathrm{PM}$ blends, in agreement with the narrower phase inversion composition range of PM blends previously observed.

\section{Mechanical Properties}

Figure 7 shows the Young's modulus against composition for both the DI and PM blends. As can be seen, both processing methods led to a similar modulus behaviour that was slightly below that predicted by the rule of mixtures. The similar modulus behaviour indicated that the different processing methods and their consequent morphology changes did not affect the mechanical behaviour at small strains.

The yield stress behaviour of both the DI and PM blends (Figure 8), as usual in polymeric materials, ${ }^{44}$ was similar to that of the Young's modulus. These yield stress values were very similar to those reported in a previous patent ${ }^{29}$ and in blends with PEI contents below 20\%. ${ }^{35}$ The values of ref 29 and 35 are shown in Figure 8 as a reference; the closest results in specimen thickness, strain rate, and test direction respect to the flow have been chosen. The lack of effect of the particle size on the modulus and yield stress of the blends of this study is due to the low strain at which they are measured, especially the moduli. This strain is usually low enough to avoid any debonding in the interface, despite the high stress concentration characteristic of large particles.

The Young's modulus-composition behaviour of Figure 7, and also that of the yield stress of Figure 8, can be due to a change in the free volume, ${ }^{45}$ to a different orientation in the blends as compared to the neat components, ${ }^{46}$ or to both effects. For this reason, the density of the blends was measured. The calculated specific volume showed a practically linear behaviour with composition discarding a positive volume of mixing as a reason for the observed negative modulus deviation. With respect to orientation, the dispersed phase of PC-rich blends was slightly oriented. However, it did not show a significant influence, as the highest negative deviation from linearity appeared at these compositions. The orientation could not be analysed by means of birefringence measurements, because the blend specimens were opaque. So, it was meas- 


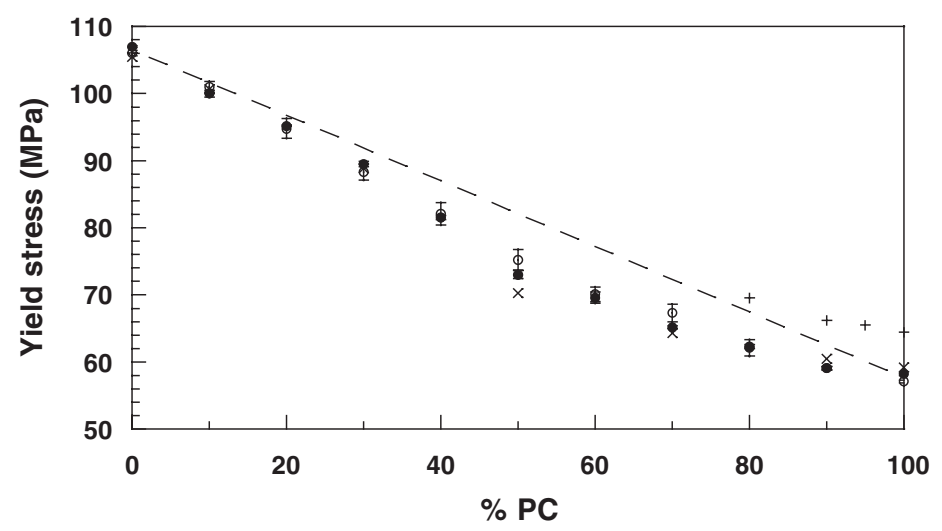

Figure 8. Yield stress of the blends as a function of the composition. Symbols as in Figure 6. Reference data from ref $29(\times)$ and ref $35(+)$.

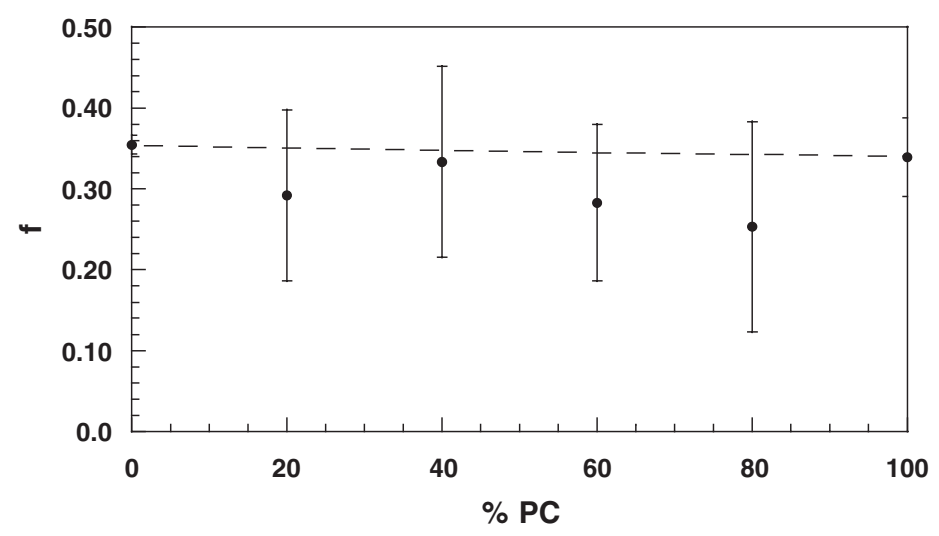

Figure 9. Orientation parameter of PM blends as a function of composition.

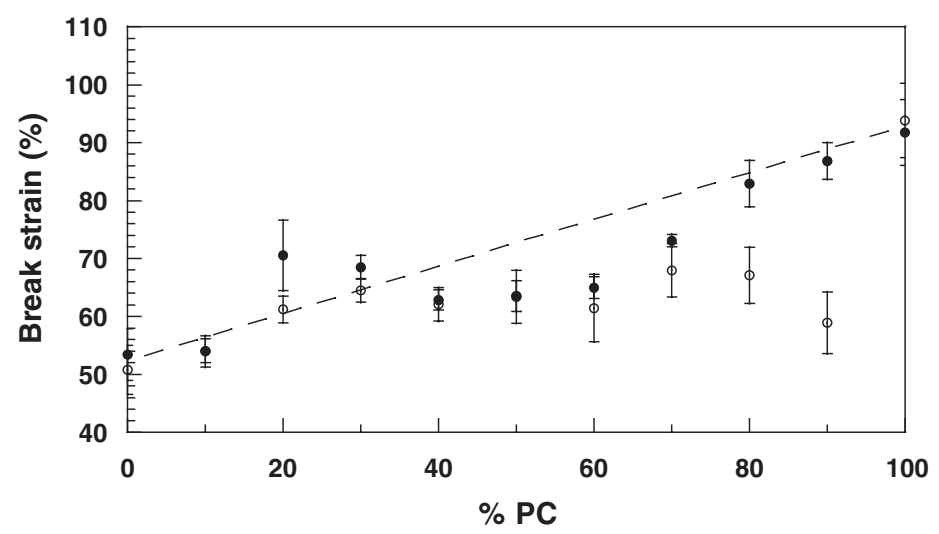

Figure 10. Break strain of the blends as a function of composition. Symbols as in Figure 6.

ured by means of the orientation parameter $(f)$ determined by FT IR for some PM compositions, and the results are shown in Figure 9. As can be seen, the orientation of the blends was close to but generally slightly below additivity, in agreement with the observed modulus-composition plot and, therefore, the modulus behaviour of the blends is mainly attributed to the slightly different orientation level of the compo- nents of the blend in the blends and in the pure state.

Figure 10 shows the break strain of the DI and PM blends against composition. The break stress showed a similar tendency from $93 \mathrm{MPa}$ (break stress of PEI) to $72 \mathrm{MPa}$ (break stress of PC). The notched impact strength in agreement with previous results ${ }^{29,35}$ was, however, very low, probably due to the high notch sensitivity of PEI. ${ }^{47}$ All the blends were ductile across 
the entire composition range and the specimens broke in the strain-hardening region of the tensile curves, in spite of the room testing temperature of the tensile tests, i.e., well below the $T_{\mathrm{g}}$ 's of both components. The existence ${ }^{48}$ of a $\gamma$ secondary transition in PC near $-100^{\circ} \mathrm{C}$ is responsible for the outstanding mechanical properties of PC and of its blends. This transition is attributed $^{49}$ to motions of the phenylene rings of the PC. PEI also shows a secondary transition at $-100^{\circ} \mathrm{C}$, which appears in all polyimides in which the rigid phenyl groups consist of rigid backbone molecules spaced with flexible groups such as methylene and ether. ${ }^{50}$ The PEI/PC blends of this work showed a $\gamma$ transition at the same temperature range as the neat components. No signs of a $\gamma$ transition suppression, which could affect negatively the blend ductility ${ }^{48}$ were observed. This explains the high ductility values obtained at room temperature. The break strain values of the PEI/PC blends of ref 29 could not be compared with those of this study, due to the very large variability of the results (from 120\% to 10\%) and to the unusually high (165\%) strain at break reported for the neat PC. As can be seen, the ductility values of DI and PM blends were similar at high and medium PEI contents, due to their rather similar morphologies. In the DI blends very rich in PC, negative deviations of ductility from linearity (not seen in PM blends) were seen; this was in agreement with the dispersed particle size, that was the highest in these blends.

As can also be seen, all PM blends, as well as DI blends with medium and high PEI contents, showed a ductility behaviour fairly close to linear whatever composition. This was unexpected for a fully immiscible blend. Considering the reasons for this positive ductility behaviour, the following possibilities appear, a) a mixing induced increase in the free volume of the blends, b) a small particle size, c) a higher orientation in the test direction in the blends than in the neat components, d) the existence of reactions between components. Besides these structural reasons, other possibilities such as e) the properties of the blend components, or f) the intrinsic nature of the blend have been also proposed.

As stated before, the free volume of the components of the blends did not change upon mixing. With respect to the particle size, the positive behaviour of ductility was mainly relevant when PEI became the continuous phase of the blends, and therefore when the dispersed phase was the finest. This could be the reason for the observed good mechanical properties, ${ }^{51}$ as large ductility values were previously seen in fully immiscible blends with fine particle sizes such as poly(ether ether ketone)/polysulfone ${ }^{52}$ and poly(ether ether ketone)/poly(ether sulfone $)^{53}$ blends. However, the ductility of the PC-rich DI blends, although smaller than that of PM blends, was also high. The particle size of the $30 / 70$ blend (mostly $2 \mu \mathrm{m}$ ) and its heterogeneity mainly ruled out a fine dispersed phase size as a reason for the positive ductility behaviour.

With respect to orientation, some different orientation of the dispersed phase of PC-rich blends was seen in the morphology section and, moreover, a slightly smaller orientation in the blends as compared with the neat components was indicated by the orientation parameters (Figure 9). However, the changes were too small to lead to significant variations in ductility. Hence, orientation can be discarded as a reason for the observed mechanical behaviour.

With respect to reactions, the differences observed in Figure 3a between the experimental and theoretical spectra indicated the occurrence of reactions. This was difficult to explain taking into account the chemical nature of the components of the blends. The fact that the $T_{\mathrm{g}}$ 's of the blends by DMTA were almost those of the pure components, indicated that the two amorphous phases were composed of a pure amorphous component, at the detection level of DMTA. However, as reacted products usually locate in the interface, slight reactions not detectable by DMTA could occur and should influence ductility. Moreover, the possibility of reaction is realistic, as a single $T_{\mathrm{g}}$ was seen in a patent $^{30}$ on PEI/PC blends after long processing time. Therefore, a possible compatibilizing effect of chemical reactions cannot be ruled out.

The stated occurrence of reactions could help to explain the ductility behaviour, but the easy stress transmission through the interface that these ductility results indicate is not very compatible with the slight reactions and lack of changes in the $T_{\mathrm{g}}$ 's. The occurrence of good ductility values in apparently fully immiscible blends is a rather frequent result. ${ }^{25,52-55}$ Therefore, other factors, such as the properties of the blend components, mentioned above, should also be taken into consideration. For instance, in a polymer blend, a lower Poisson's ratio or a higher thermal expansion coefficient of the matrix lead to compressive stress in the dispersed phase upon elongation, making debonding difficult. However, provided these effects help ductility when one component is the matrix, they should be detrimental when the matrix is the other. Therefore, when the positive ductility values take place whatever the composition, a different Poisson's ratio or thermal expansion coefficient cannot be the reason for good ductility behaviour.

Finally, a highly aromatic character of both components of the blend $d^{25,52,53,55}$ has been proposed as the reason for compatibility in fully immiscible blends such as PPS with both PEI and PSU, ${ }^{25}$ and PEEK with both PSU ${ }^{52,55}$ and PES. ${ }^{53}$ Both components of PEI/PC 
blends are also highly aromatic, with bisphenol A units in their polymer chains. Thus, the behaviour of this blend agrees with this proposition, and could therefore account for the mechanical behaviour of these blends.

\section{CONCLUSIONS}

The PEI/PC blends studied have two pure amorphous phases whatever the mixing procedure. An anomalous decrease in the high temperature $T_{\mathrm{g}}$ of the $90 / 10$ and $80 / 20$ compositions was seen in the PM blends, but not in the DI blends. Therefore, parameters such as particle size, degradation, or reactions were ruled out as responsible for this anomalous decrease, that was attributed mainly to an anomalous thermodynamic behaviour.

The fast DI mixing procedure led to a mostly fine but heterogeneous morphology in PC-rich blends. This did not influence either the modulus of elasticity or the yield stress that were very close to linearity whatever the composition and processing procedure. The ductility of the DI blends rich in PC was slightly smaller than that of PM blends, but all the blends showed a ductility behaviour close to linearity, unexpected in apparently fully phase separated blends. Having ruled out a higher specific volume or orientation in the blends, or particle size, this positive behaviour was attributed to the slight reactions seen by FT IR and to the highly aromatic nature of the components of the blend.

Acknowledgment. The financial support of the Basque Government (ETORTEK Research Program, 2003) is gratefully acknowledged. J. Ramiro also acknowledges the Basque Government for the award of a grant for the development of this work.

\section{REFERENCES}

1. D. R. Paul and C. B. Bucknall, Ed., "Polymer Blends," Wiley Interscience, New York, N.Y., 2000.

2. L. A. Utracki, Ed., "Polymer Blends Handbook," Kluwer Academic Publishers, London, U.K., 2002.

3. R. E. Fines and J. Bartolomucci, "Engineered Materials Handbook, Vol. 2: Engineering Plastics," ASM International, Metals Park, OH, 1988, pp 156-158.

4. J. E. Harris and L. M. Robeson, J. Appl. Polym. Sci., 35, 1877 (1988).

5. G. Crevecoeur and G. Groeninckx, Macromolecules, 24, 1190 (1991).

6. H. L. Chen and R. S. Porter, Polym. Eng. Sci., 32, 1870 (1992).

7. J. C. Kim, M. Cakmak, and P. H. Geil, SPE Antec Tech. Pap., 43, 1572 (1997).
8. H. L. Chen, J. C. Hwang, and R. C. Wang, Polymer, 39, 6067 (1998).

9. S. Bikakci and M. Cakmak, Polymer, 39, 4001 (1998).

10. E. M. Woo and S. N. Yau, Macromolecules, 30, 3626 (1997).

11. H. L. Chen, J. C. Hwang, C. C. Chen, R. C. Hwang, D. M. Fang, and M. J. Tsai, Polymer, 38, 2747 (1997).

12. J. Jang and K. Sim, Polym. Test., 17, 517 (1998).

13. F. J. Vallejo, J. I. Eguiazábal, and J. Nazábal, J. Appl. Polym. Sci., 80, 885 (2001).

14. J. M. Martínez, J. I. Eguiazábal, and J. Nazábal, J. Appl. Polym. Sci., 48, 935 (1993).

15. W. H. Jo, M. R. Lee, B. G. Min, and M. S. Lee, Polym. Bull., 33, 113 (1994).

16. H. L. Chen, Macromolecules, 28, 2845 (1995).

17. J. M. Martínez, J. I. Eguiazábal, and J. Nazábal, J. Appl. Polym. Sci., 62, 385 (1996).

18. Y. H. Kuo, E. M. Woo, and T. Y. Kuo, Polym. J., 33, 920 (2001).

19. J. M. Huang and F. C. Chang, J. Appl. Polym. Sci., 84, 850 (2002).

20. J. Ramiro, J. I. Eguiazábal, and J. Nazábal, Polym. Adv. Technol., 14, 129 (2003).

21. S. Bastida, J. I. Eguiazábal, and J. Nazábal, Eur. Polym. J., 32, 1229 (1996).

22. S. Bastida, J. I. Eguiazábal, and J. Nazábal, Polymer, 37, 2317 (1996).

23. K. Y. Choi, S. G. Lee, and J. H. Lee, Polym. Eng. Sci., 35, 1643 (1995).

24. J. H. Lee, S. G. Lee, K. Y. Choi, and J. Liu, Polym. J., 30, 531 (1998).

25. S. Akhtar and J. L. White, Polym. Eng. Sci, 31, 84 (1991).

26. L. A. Utracki, Ed., "Commercial Polymer Blends," Chapman \& Hall, New York, N.Y., 1998.

27. H. T. Pham, S. Munjal, and C. P. Bosnyak, in "Handbook of Thermoplastics," O. Olabisi, Ed., Marcel Dekker, New York, N.Y., 1997, chapt. 26.

28. R. S. Porter and L. H. Wang, Polymer, 33, 2019 (1992).

29. G. A. Mellinger, H. F. Giles, F. F. Holub, and W. R. Schilich, WO Patent 8404752 (1984).

30. E. N. Peters and J. A. Rock, Eur. Patent 0325719 (1989).

31. J. A. Rock, N. E. Durfee, and R. O. Johnson, Eur. Patent 0186243 (1986).

32. J. A. Rock, U.S. Patent 4629759 (1986).

33. Y. S. Chun, H. S. Lee, W. N. Kim, and T. S. Oh, Polym. Eng. Sci., 36, 2694 (1996).

34. M. Zhang, P. Choi, and U. Sundararaj, Polymer, 44, 1979 (2003).

35. W. G. Kohlman and S. P. Petrie, Adv. Polym. Technol., 14, 111 (1995).

36. Y. S. Chun, H. S. Kwan, W. N. Kim, and H. G. Yoon, J. Appl. Polym. Sci., 78, 2488 (2000).

37. J. I. Eguiazábal and J. Nazábal, Eur. Polym. J., 25, 891 (1989).

38. S. Bastida, J. I. Eguiazábal, and J. Nazábal, J. Appl. Polym. Sci., 63, 1601 (1997).

39. W. J. MacKnight, F. E. Karasz, and J. R. Fried, in "Polymer Blends," D. R. Paul and S. Newman, Ed., Academic Press, New York, N.Y., 1978, chapt. 5. 
40. I. N. Razinskaya, L. I. Batueva, B. S. Tyves, L. A. Smirnova, and B. P. Shtarkman, Kolloidn. Zh., 37, 672 (1975).

41. W. Bu and J. He, J. Appl. Polym. Sci., 62, 1445 (1996).

42. B. D. Favis, in "Polymer Blends," D. R. Paul and C. B. Bucknall, Ed., Wiley Interscience, New York, N.Y., 2000, chapt. 16.

43. S. Bastida, J. I. Eguiazábal, and J. Nazábal, Polym. Test., 12, 233 (1993).

44. N. Brown, in "Failure of Plastics," W. Brostow and R. D. Corneliussen, Ed., Hanser Publishers, Munich, 1986, chapt. 6.

45. L. W. Kleiner, F. E. Karasz, and W. J. Macknight, Polym. Eng. Sci., 19, 519 (1979).

46. J. I. Eguiazábal and J. Nazábal, Plast., Rubber Compos. Process. Appl., 14, 211 (1990).

47. H. Domininghaus, Ed., "Plastics for Engineers: Materials,
Properties, Applications," Hanser Publishers, Munich, 1993.

48. M. Gaztelumendi and J. Nazábal, Polym. Eng. Sci., 40, 430 (2000).

49. A. F. Yee and S. A. Smith, Macromolecules, 14, 54 (1981).

50. J. K. Gillham, K. D. Hallock, and S. J. Stadnicki, J. Appl. Polym. Sci., 16, 2595 (1972).

51. M. Hara and J. A. Sauer, J. Macromol. Sci., Part C: Rev. Macromol. Chem. Phys., 38, 327 (1998).

52. A. Arzak, J. I. Eguiazábal, and J. Nazábal, J. Appl. Polym. Sci., 65, 1503 (1997).

53. A. Arzak, J. I. Eguiazábal, and J. Nazábal, J. Appl. Polym. Sci., 58, 653 (1995).

54. A. Arzak, J. I. Eguiazábal, and J. Nazábal, J. Mater. Sci., 26, 5939 (1991).

55. A. Arzak, J. I. Eguiazábal, and J. Nazábal, Macromol. Chem. Phys., 198, 1829 (1997). 